\title{
Analysis of factors affected the SARS-CoV-2 viral shedding time of COVID-19 patients in Anhui, China: a retrospective study
}

You-Hui Tu

Anhui Medical University

Yuan-Yuan Wei

Anhui Medical University

Da-Wei Zhang

Anhui Medical University

Chang-Shan Chen

Anhui Medical University

Xian-Wei Hu ( $\nabla$ huxianwei72@sina.com )

Anhui Medical University

GuangHe Fei ( $\nabla$ guanghefei@126.com )

First Affiliated Hospital of Anhui Medical University https://orcid.org/0000-0003-0064-2073

Research

Keywords: SARS-CoV-2, COVID-19, Viral shedding

Posted Date: April 6th, 2020

DOl: https://doi.org/10.21203/rs.3.rs-20954/v1

License: (9) (i) This work is licensed under a Creative Commons Attribution 4.0 International License.

Read Full License 


\section{Abstract}

Background The epidemic of Severe Acute Respiratory Syndrome Coronavirus-2 (SARS-CoV-2) has spread worldwide, but the factors that may affect the SARS-CoV-2 viral shedding time in coronavirus disease 2019 (COVID-19) patients were rarely reported. Methods We retrospectively recruited 40 confirmed common COVID-19 patients and classified them into two groups according to the SARS-CoV-2 viral shedding time (group A (less than 10 days) and group B (10 days or more)). The demographic, laboratory parameters and chest computed tomography (CT) features on admission and the 3 rd day after treatment were analyzed respectively. Results Fourteen patients were in group A and 26 patients in group B, the median SARS-CoV-2 viral shedding time of the two groups was 7 and 16 days respectively. Compared to the group $A$, the comorbidity, epidemiological risk history, serum glucose and CD4/8 on admission were significantly higher in the group $B(P<0.05)$. On the 3 rd day after treatment, the group $B$ got significantly higher IL-6, IL-2R, TNF- $a$ and CD4/8, and lower platelet and CD8 + T lymphocyte counts than group $A(P<0.05)$. Logistic regression analyses revealed that the higher epidemiological risk history, serum glucose and CD4/8 on admission were significantly associated with a longer SARS-CoV-2 viral shedding time (OR=7.5, 11.41, 9.21 respectively, $P<0.05)$, as well as the higher TNF-a and lower CD8 $+T$ lymphocytes on the $3 \mathrm{rd}$ day after treatment $(\mathrm{OR}=2.36,0.98$ respectively, $\mathrm{P}<0.05)$. Conclusions Our study provides the evidence that the prolonged SARS-CoV-2 viral shedding time might be correlated with the patients' epidemiological risk history, as well as the serum glucose and CD4/8 on admission, TNF-a and CD8 $+\mathrm{T}$ lymphocytes on the $3 \mathrm{rd}$ day after treatment. Our result may help clinicians to distinguish the patients with a prolonged viral shedding time at the early stage.

\section{Introduction}

Since December 2019, several cases of pneumonia caused by SARS-CoV-2 (Severe Acute Respiratory Syndrome Coronavirus-2), which recently named as COVID-19 (coronavirus disease 2019) by World Health Organization (WHO) have been reported in Wuhan, Hubei province, China. The disease has rapidly spread to the other cities of China, as well as the other countries worldwide [1, 2]. Until March 31, 2020, the 2019-nCoV has caused more than eighty-two thousand cases in China, including more than nine hundred cases in Anhui province. Numerous studies have reported the clinical characteristics of COVID19 patients [3-6]. However, factors that relevant to the therapeutic effects or prognosis of COVID-19 patients were rarely reported, especially the factors that may affect the SARS-CoV-2 viral shedding. Nucleic acid test is not only important for the diagnosis and discharge of COVID-19 patients, but also an important evaluation index of disease severity and prognosis [7]. Here, we retrospectively analyzed the SARS-CoV-2 viral shedding time of 40 COVID-19 patients in Anhui province, and explored the clinical factors that may affect the SARS-CoV-2 viral shedding time.

\section{Methods}

\section{Patients involvement and data collection}


All hospitalized patients ( $n=40)$ (admission date from Jan 26th to Feb 23rd 2020) in the first affiliated hospital of Anhui Medical University and the first people's hospital of Chuzhou City were recruited in this study, diagnosed as "COVID-19" according to the diagnostic and treatment guideline of SARS-CoV-2 issued by the Chinese National Health Committee (Version 4-6). The epidemiological risks included: a history of travel to or residence in Wuhan city, China or other cities with continuous transmission of local cases in the last two weeks before symptoms onset; contact with patients with fever or respiratory symptoms from Wuhan city, China or other cities with continuous transmission of local cases in the last two weeks before symptoms onset; or epidemiologically connected to 2019-nCoV infections or clustered onsets.

Demographic information, incubation period (the time delay from infection to illness onset), clinical characteristics (including medical history, comorbidity, surgery history, signs and symptoms), chest computed tomography (CT) scan or X-ray results and laboratory findings of each patient were obtained from the electronical medical record system. The study was performed according to the Declaration of Helsinki and approved by the institutional ethics board of the first affiliated hospital of Anhui Medical University (Quick-PJ 2020-02-12), and all patients signed the informed consent.

The date of disease onset and hospital admission date, as well as the severity of COVID-19 were also recorded. The onset date was defined as the day when any symptoms were noticed by the patients. Severity of COVID-19 was defined according to the diagnostic and treatment guideline of SARS-CoV-2 issued by the Chinese National Health Committee (Version 4-6). The clinical classifications are as follows: (1) mild, with fever, respiratory symptoms, but no pneumonia in CT image. (2) common, with fever, respiratory symptoms, and imaging shows pneumonia. (3) moderate, meet any of the following criteria: 1) Respiratory rate $\geq 30$ beats/min; 2) Pulse Oximeter Oxygen saturation $\leq 93 \%$ at rest; 3 ) Oxygenation index (artery partial pressure of oxygen fraction, $\mathrm{PaO} 2 / \mathrm{FiO} 2$ ) $\leq 300 \mathrm{mmHg}$. (4) severe, meet any of the following conditions:1) respiratory failure occurs and requires mechanical ventilation; 2) shock occurs; 3) ICU admission is required for combined organ failure.

\section{Laboratory testing}

Hematology examination, respiratory virus nucleic acid, liver and kidney function, C-reactive protein (CRP), lactate, D-dimer, fibrinogen, inflammatory cytokines ((interleukin(IL)-6, IL-2R, Tumor Necrosis Factor $a(T N F-a)), C D 4^{+}$and $C D 8^{+} T$ lymphocytes counts etc were examined on the hospital admission date and re-examined every 3 to 5 days after treatment.

Patients' pharyngeal swab specimens were collected for the SARS-CoV-2 viral nucleic acid examination on the hospital admission date and re-examined every other day after the 3 days' treatment. All medical laboratory data were generated by the clinical laboratory of the first affiliated hospital of Anhui Medical University and the first people's hospital of Chuzhou City.

\section{Chest imaging examination}


All patients took the chest CT on the hospital admission date and re-examined every 3 to 5 days after treatment to assess the disease progression and therapeutic effect. Disease progression and therapeutic effect assessed by the CT imaging can be classified into 5 degrees compared with the original CT imaging, -2: pulmonary lesion area increased more than $50 \%$; -1 : pulmonary lesion area increased less than $50 \%$; 0 : no change; 1 : pulmonary lesion area decreased less than $50 \%$; 2 : pulmonary lesion area decreased more than $50 \%$.

\section{Treatment}

All patients were treated according to the diagnostic and treatment guideline of SARS-CoV-2 issued by the Chinese National Health Committee (Version 4-6). Antiviral medicine includes a-interferon atomization inhalation (5 million $\mathrm{U}$, twice daily), lopinavir/ritonavir orally (500 mg, twice daily), arbidol orally ( 0.2 gram, three times a day). Other treatment such as oxygen therapy was administered if the patients had hypoxemia. The patients were re-examined for symptoms, laboratory indexes and chest imaging at indicated times during the treatment period.

The primary target in this study was the SARS-CoV-2 viral shedding time, which was calculated by the date of diagnosis and respiratory nucleic acid convert to negative for two consecutive times at an interval of one day. Meanwhile, we set the cut-off of viral shedding time as 10 days and classified the patients into two groups (group A (less than 10 days) and group B (10 days or more)).

\section{Statistical analysis}

Categorical variables were described as frequencies and percentages, continuous variables were described as means and standard deviations or median and interquartile ranges (IQR). To compare the continuous variables for data of different groups, two-tailed t-test and Mann-Whitney test were used. The frequencies of categorical variables were compared using the chi-square and Fisher's exact test. Multivariable Logistic analysis was conducted to evaluate the association of demographic, laboratory measurements and nucleic acid conversion time. All statistical analyses were generated using SPSS software version 16 (Statistical Product and Services Solutions). The P value less than 0.05 was considered statistically significant.

\section{Results}

All of the 40 COVID-19 patients included in this study were diagnosed as common group (clinical classification) on admission. According to the SARS-CoV-2 viral shedding time, 14 patients were in group A and 26 patients in group B. The median SARS-CoV-2 viral shedding time of the two groups was 7 (3-9) and 16 (10-36) days respectively. 19 (47.5\%) patients had a history of travel to or residence in Wuhan in the last two weeks, and 12(30\%) patients had a close exposure history with confirmed COVID-19 patients in the last two weeks. All patients were tested for nine respiratory pathogens, nucleic acid of influenza $A$ and $B$, and the bacteria and fungi culture. No other respiratory virus, bacteria or fungi infection were found in any of the patients. 9(22.5\%) patients had comorbidities, including diabetes, hypertension, 
obstructive sleep apnea syndrome (OSAS), chronic hepatitis B (CHB), and hyperlipemia (one person had both hypertension and diabetes). Among the 40 patients, 34(85\%) cases had fever, 20(50\%) cases had cough, $9(22.5 \%)$ cases had sputum, $5(12.5 \%)$ cases had mild chest tightness after exercise, $6(15 \%)$ cases had fatigue, $1(2.5 \%)$ case had diarrhea and $2(5 \%)$ case had sore throat. The two groups were similar with respect to age, sex, BMl, signs and symptoms, incubation period and treatment as shown in Table 1 (P区 0.05), but group B exhibited a higher rate of epidemiological risk history and comorbidity compared to group A (P区0.05).

The results of laboratory tests and CT features on admission were compared between two groups, as shown in Table 2. After examined with the chest CT, 28(70\%) patients had bilateral pneumonia, 7(17.5\%) patients had unilateral pneumonia, and $5(12.5 \%)$ patients had no pulmonary lesion on the chest CT imaging. Most of the patients exhibited normal level of whole blood cell count, but no statistical differences were seen in white blood cell count, neutrophil count, lymphocyte count, neutrophil to lymphocyte ratio (NLR) and hemoglobin between the two groups. However, group B had a significant lower CRP, platelet count and platelet to lymphocyte ratio (PLR) compared to group A (P凶0.05). There were no significant differences in liver and kidney function tests between two groups, as well as fibrinogen, D-dimer, inflammatory cytokines (IL-6, IL-2R, TNF-a), CD $4^{+}$and $C D 8^{+} T$ lymphocyte counts and chest $\mathrm{CT}$ features. However, the group $\mathrm{B}$ had a significantly higher $\mathrm{CD} 4$ to $C D 8^{+} \mathrm{T}$ lymphocyte counts ratio $(C D 4 / 8)$ and serum glucose compared to group $A(P \otimes 0.05)$. The detailed laboratory measurements were shown in Table 2.

\section{Comparisons of laboratory tests and CT features on the $3^{\text {rd }}$ day after treatments}

All patients had re-examined laboratory tests and chest CT on the $3^{\text {rd }}$ day after treatments. Consistent with the result on admission, the group B still had significantly higher CD4/8, lower platelet count and PLR compared to group $A(P \otimes 0.05)$. Different from the results on admission, the group $B$ had a significantly higher level of inflammatory cytokines (IL-6, IL-2R and TNF-a) and lower level of CD8 ${ }^{+} T$ lymphocyte count than group A (P凶0.05). The detailed measurements of the two groups were shown in Table 3.

When compared the changes of chest CT features, the pulmonary lesion of $19(47.5 \%)$ patients had no change on the CT imaging, 3 (7.5\%) patients had an increase more than $50 \%, 5(12.5 \%)$ patients had an increase less than $50 \%, 11(27.5 \%)$ patients had a decrease less than $50 \%$ and $2(5 \%)$ patients had a decrease more than $50 \%$. The CT imaging had a significant improvement in the group A compared to group $B(P=0.02)$, typical changes of the chest $C T$ imaging in COVID-19 patients were shown in Figure 1 .

\section{Logistic analysis of clinical measurements}

As shown in Table 4, multivariable logistic analyses were conducted to evaluate the association of the demographic and laboratory measurements and the viral shedding time. We demonstrated that the epidemiological risk history, higher serum glucose and $\mathrm{CD} 4 / 8$ on admission were significantly associated 
with a longer viral shedding time $(\mathrm{OR}=7.5,11.41,9.21$, respectively, $\mathrm{P} \bigotimes 0.05)$, as well as the higher level of TNF-a and lower $C D 8^{+} T$ lymphocytes on the $3^{\text {rd }}$ day after treatment $(\mathrm{OR}=2.36,0.98$, respectively, $\mathrm{P} \otimes 0.05)$.

\section{Discussion}

The SARS-CoV-2 nucleic acid convert to negative is an essential criterion for COVID-19 patients to discharge from hospital. In the clinical treatment, we found there were many patients whose respiratory nucleic acid remained positive, although their symptoms and CT imaging had improved significantly. In this study, we retrospectively classified the 40 mild COVID-19 patients into two groups according to the SARS-CoV-2 viral shedding time and set the cut-off value as 10 days. We found the SARS-CoV-2 viral shedding time was significantly affected by patients' epidemiological risk history, as well as the serum glucose and CD4/8 on admission. Meanwhile, the inflammatory cytokines TNF-a, CD8 ${ }^{+} T$ lymphocytes and changes of CT imaging on the 3rd day after treatment may also affect the viral shedding time.

Coronaviruses mainly cause respiratory infections, and some strains have high infectivity and mortality, such as the severe acute respiratory syndrome (SARS) and middle east respiratory syndrome (MERS) [8, 9]. SARS-CoV-2 belongs to the betacoronavirus and has enveloped virions with 60-140 $\mathrm{nm}$ in diameter. Previous studies have demonstrated the human-to-human transmission of SARS-CoV-2 [10-13], but its transmission rates, origin or the time span of viral shedding are unknown till now. In this study, we demonstrated that most of the patients had a visit or resident history of Wuhan, or had a close contact with confirmed COVID-19 patients, which was consistent with previous studies [5, 12]. Meanwhile, we found that patients with more than 10 days of viral shedding time had a significantly higher rate of epidemiological risk history than those less than 10 days $(92.3 \%$ versus $50 \%, P=0.004)$, which indicated that the epidemiological risk history might affect the SARS-CoV-2 viral shedding time. The host's immune status is an important factor for disease recovery. In this study, we observed a higher rate of comorbidity in patients with more than 10 days of viral shedding time, which could be attributed to their deficiency of immune system, including the humoral and cellular immunity. Meanwhile, multivariable regression analyses revealed that the level of serum glucose was significantly higher in patients with more than 10 days of viral shedding time, a possible explaination maybe that the viral infection and replication affect the secretion of glucagon and insulin. Our results suggested that SARS-CoV-2 is more likely to replicate and infect people with chronic comorbidities (especially diabetes) as a result of their weaker immune functions.

The typical hematology examination of COVID-19 patients often displayed normal or decreased leukocytes, with decreased lymphocyte count, severe patients may accompanied with decreased platelet count $[7,14]$. Consistent with previous studies $[5,15]$, most patients in our study had decreased lymphocyte count, which indicated that the SARS-CoV-2 mainly act on the lymphocyte. The decreased lymphocyte count was related to the progression of disease, and we proposed that blood lymphocyte related index maybe a potential predictor of viral shedding. Both PLR and NLR were widely used to assess the severity of bacterial infections and the prognosis of tumor patients [16, 17], and the increased PLR or NLR often predicts poor clinical prognosis. Liu and colleagues have demonstrated that the 
increased NLR might help to identify the severe COVID-19 patients at the early stage [18]. However, our results demonstrated that the PLR was significantly lower in patients with more than 10 days of viral shedding, the reason was controversial and we speculate the lower PLR might attribute to the lower platelet count.

T lymphocyte plays an important role in the cellular immunity and inflammatory response against coronavirus infection $[19,20]$. Numerous studies have demonstrated the important role that inflammatory cytokine storm played in the pathology of COVID-19 [21, 22]. In this study, the T lymphocyte counts and inflammatory cytokines were measured both on admission and the 3rd day after treatment. Interestingly, patients whose viral shedding time more than 10 days had significantly higher levels of inflammatory cytokines (IL-6, IL-2R and TNF-a) and lower CD8 ${ }^{+} T$ lymphocytes after 3 days' treatment, but not on admission. Moreover, the multivariable regression analyses revealed that the higher TNF- $a$ and lower $\mathrm{CD} 8^{+} \mathrm{T}$ lymphocytes may be risk factors for viral shedding. Since there was no difference in treatment given between two groups, we speculate that the delayed viral shedding might correlate with the stronger inflammatory response and lower sensitivity to the treatment. The chest CT feature is an essential component to assess the severity of COVID-19 [7]. Wu and colleagues have demonstrated that the CT images of COVID-19 patients correlated well with the pulmonary inflammation index and lymphocyte [23]. Consistent with our results of inflammatory cytokines, patients with more than 10 days of viral shedding had less improved CT imaging, and some of these patients even had more pulmonary lesion after 3 days' of treatment. This result indicated that the changes of chest CT imaging at early stage may predict the viral shedding time, but more studies are needed for verification.

There are several limitations in this study. Firstly, this was a double center study, but only 40 common COVID-19 patients were included. More patients (especially asymptomatic and severe patients) in Anhui or other provinces should be recruited to get a more comprehensive and convincible conclusion. Secondly, detailed information about follow-up was lacking, especially the nucleic acid of recovered patients may test "re-positive" after discharge from hospital. In this study, there was no patients tested "re-positive" till the end of research, and follow-up will be conducted in the next 6 months.

\section{Conclusion}

In summary, the SARS-CoV-2 viral shedding can be affected by many factors. Our study provide the clinical and epidemiological evidence that the prolonged SARS-CoV-2 viral shedding time might be correlated with the patients' epidemiological risk history, as well as the serum glucose and CD $4 / 8$ on admission, TNF-a and CD $8^{+} \mathrm{T}$ lymphocytes on the 3rd day after treatment. Our conclusion may help clinicians to distinguish the patients with a prolonged SARS-CoV-2 viral shedding time at the early stage.

\section{Abbreviations}

SARS-CoV-2: Severe Acute Respiratory Syndrome Coronavirus-2; COVID-19: coronavirus disease 2019; WHO: World Health Organization; IL-6: interleukin-6; IL-2R: interleukin-2R; TNF-a: Tumor Necrosis Factor a; 
NLR: neutrophil to lymphocyte ratio; PLR: platelet to lymphocyte ratio; CT: computed tomography; CRP: Creactive protein; ICU: intensive care unit; SPSS: Statistical Product and Services Solutions; IQR: interquartile ranges; BMI: body mass index; OSAS: obstructive sleep apnea syndrome; CHB: chronic hepatitis B; MERS: middle east respiratory syndrome.

\section{Declarations}

\section{Acknowledgments}

We thank the clinical laboratory and the radiology department of the first affiliated hospital of Anhui Medical University and the first people's hospital of Chuzhou City for the measurements of laboratory tests and CT imaging.

\section{Authors Contributions}

Guang-He Fei conceived and designed the study, and took responsibility for the integrity of the data and the accuracy of the data analysis. Xian-Wei Hu, and Chang-Shan Chen assisted in data collection. YuanYuan Wei and Da-Wei Zhang analysed the data. You-Hui Tu interpreted the data and contributed to the writing of the final version of the manuscript. All authors agreed with the results and conclusions of this article.

\section{Funding}

This work was funded by the National Natural Science Foundation of China (81870036) and the Key Technology Research and Development Program of Anhui Province (1804h08020237).

\section{Availability of data and materials}

All data generated or analyzed during this study are included in this published article. And the datasets generated and analyzed during the current study are available from the corresponding author on reasonable request.

\section{Ethics approval and consent to participate}

Ethics Committee of the first affiliated hospital of Anhui Medical University approved this study.

\section{Consent for publication}

Not applicable.

\section{Conflict of interests}

All authors declare no competing interests. 


\section{References}

1. Holshue ML, DeBolt C, Lindquist S, Lofy KH, Wiesman J, Bruce H, Spitters C, Ericson K, Wilkerson S, Tural A, et al. First Case of 2019 Novel Coronavirus in the United States. N Engl J Med. 2020 Mar 5;382(10):929-36.

2. Thanh HN, Van TN, Thu HNT, Van BN, Thanh BD, Thu HPT, Kieu ANT, Viet NN, Marks GB, Fox GJ, et al. Outbreak investigation for COVID-19 in northern Vietnam. Lancet Infect Dis. 2020 Mar 4.

3. Chen N, Zhou M, Dong X, Qu J, Gong F, Han Y, Qiu Y, Wang J, Liu Y, Wei Y, et al. Epidemiological and clinical characteristics of 99 cases of 2019 novel coronavirus pneumonia in Wuhan, China: a descriptive study. Lancet. 2020 Feb 15;395(10223):507-13.

4. Huang C, Wang Y, Li X, Ren L, Zhao J, Hu Y, Zhang L, Fan G, Xu J, Gu X, et al. Clinical features of patients infected with 2019 novel coronavirus in Wuhan, China. The Lancet. 2020;395(10223):497506.

5. Guan WJ, Ni ZY, Hu Y, Liang WH, Ou CQ, He JX, Liu L, Shan H, Lei CL, Hui DSC, et al. Clinical Characteristics of Coronavirus Disease 2019 in China. N Engl J Med. 2020 Feb 28.

6. Zhang G, Zhang J, Wang B, Zhu X, Wang Q, Qiu S. Analysis of clinical characteristics and laboratory findings of 95 cases of 2019 novel coronavirus pneumonia in Wuhan, China: a retrospective analysis. Respir Res. 2020 Mar 26;21(1):74.

7. Jin YH, Cai L, Cheng ZS, Cheng H, Deng T, Fan YP, Fang C, Huang D, Huang LQ, Huang Q, et al. A rapid advice guideline for the diagnosis and treatment of 2019 novel coronavirus (2019-nCoV) infected pneumonia (standard version). Mil Med Res. 2020 Feb 6;7(1):4.

8. Meo SA, Alhowikan AM, Al-Khlaiwi T, Meo IM, Halepoto DM, Iqbal M, Usmani AM, Hajjar W, Ahmed N. Novel coronavirus 2019-nCoV: prevalence, biological and clinical characteristics comparison with SARS-CoV and MERS-CoV. Eur Rev Med Pharmacol Sci. 2020 Feb;24(4):2012-9.

9. Peeri NC, Shrestha N, Rahman MS, Zaki R, Tan Z, Bibi S, Baghbanzadeh M, Aghamohammadi N, Zhang W, Haque U. The SARS, MERS and novel coronavirus (COVID-19) epidemics, the newest and biggest global health threats: what lessons have we learned? Int J Epidemiol. 2020 Feb 22.

10. Li Q, Guan X, Wu P, Wang X, Zhou L, Tong Y, Ren R, Leung KSM, Lau EHY, Wong JY, et al. Early Transmission Dynamics in Wuhan, China, of Novel Coronavirus-Infected Pneumonia. N Engl J Med. 2020 Jan 29.

11. Lillie PJ, Samson A, Li A, Adams K, Capstick R, Barlow GD, Easom N, Hamilton E, Moss PJ, Evans A, et al. Novel coronavirus disease (Covid-19): the first two patients in the UK with person to person transmission. J Infect. 2020 Feb 28.

12. Chan JF, Yuan S, Kok KH, To KK, Chu H, Yang J, Xing F, Liu J, Yip CC, Poon RW, et al. A familial cluster of pneumonia associated with the 2019 novel coronavirus indicating person-to-person transmission: a study of a family cluster. Lancet. 2020 Feb 15;395(10223):514-23.

13. Phan LT, Nguyen TV, Luong QC, Nguyen TV, Nguyen HT, Le HQ, Nguyen TT, Cao TM, Pham QD. Importation and Human-to-Human Transmission of a Novel Coronavirus in Vietnam. N Engl J Med. 
2020 Feb 27;382(9):872-4.

14. Bermejo-Martin JF, Almansa R, Menendez R, Mendez R, Kelvin DJ, Torres A. Lymphopenic community acquired pneumonia as signature of severe COVID-19 infection: Lymphopenia in severe COVID-19 infection. J Infect. 2020 Mar 4.

15. Wang D, Hu B, Hu C, Zhu F, Liu X, Zhang J, Wang B, Xiang H, Cheng Z, Xiong Y, et al. Clinical Characteristics of 138 Hospitalized Patients With 2019 Novel Coronavirus-Infected Pneumonia in Wuhan, China. JAMA. 2020 Feb 7.

16. Ge YL, Zhang HF, Zhang Q, Zhu XY, Liu CH, Wang N, Zhang JB, Chen H, Chen Y, Li WQ, et al. Neutrophil-to-Lymphocyte Ratio in Adult Community-Acquired Pneumonia Patients Correlates with Unfavorable Clinical Outcomes. Clin Lab. 2019 May 1;65(5).

17. Diem S, Schmid S, Krapf M, Flatz L, Born D, Jochum W, Templeton AJ, Fruh M. Neutrophil-toLymphocyte ratio (NLR) and Platelet-to-Lymphocyte ratio (PLR) as prognostic markers in patients with non-small cell lung cancer (NSCLC) treated with nivolumab. Lung Cancer. 2017 Sep;111:176-81.

18. Liu J, Liu Y, Xiang P, Pu L, Xiong H, Li C, Zhang M, Tan J, Xu Y, Song R, et al. Neutrophil-toLymphocyte Ratio Predicts Severe Illness Patients with 2019 Novel Coronavirus in the Early Stage. medRxiv. 2020:2020.02.10.20021584.

19. Janice Oh HL, Ken-En Gan S, Bertoletti A, Tan YJ. Understanding the T cell immune response in SARS coronavirus infection. Emerg Microbes Infect. 2012 Sep;1(9):e23.

20. Liu WJ, Zhao M, Liu K, Xu K, Wong G, Tan W, Gao GF. T-cell immunity of SARS-CoV: Implications for vaccine development against MERS-CoV. Antiviral Res. 2017 Jan;137:82-92.

21. Tian S, Hu W, Niu L, Liu H, Xu H, Xiao SY. Pulmonary pathology of early phase 2019 novel coronavirus (COVID-19) pneumonia in two patients with lung cancer. J Thorac Oncol. 2020 Feb 27.

22. Xu Z, Shi L, Wang Y, Zhang J, Huang L, Zhang C, Liu S, Zhao P, Liu H, Zhu L, et al. Pathological findings of COVID-19 associated with acute respiratory distress syndrome. The Lancet Respiratory Medicine. 2020.

23. Wu J, Wu X, Zeng W, Guo D, Fang Z, Chen L, Huang H, Li C. Chest CT Findings in Patients with Corona Virus Disease 2019 and its Relationship with Clinical Features. Invest Radiol. 2020 Feb 21.

\section{Tables}

Table 1. Comparisons of demographic and clinical measurements between two groups 


\begin{tabular}{|c|c|c|c|}
\hline Characteristics & $\begin{array}{c}\text { Group A } \\
(\mathrm{n}=14)\end{array}$ & $\begin{array}{c}\text { Group B } \\
(n=26)\end{array}$ & $\mathrm{P}$ value \\
\hline Age, years & $40.86 \pm 8.26$ & $45.50 \pm 14.60$ & 0.28 \\
\hline Gender(F/M) & $8 / 6$ & $11 / 15$ & 0.51 \\
\hline $\operatorname{BMI}\left(\mathrm{kg} / \mathrm{m}^{2}\right)$ & $23.74 \pm 2.86$ & $24.33 \pm 3.28$ & 0.58 \\
\hline Comorbidity & $0(0)$ & $9(34.62 \%)^{*}$ & 0.016 \\
\hline Diabetes & $0(0)$ & $2(7.7)$ & \\
\hline Hypertension & $0(0)$ & $5(19.2)$ & \\
\hline OSAS & $0(0)$ & $1(3.8)$ & \\
\hline $\mathrm{CHB}$ & $0(0)$ & $1(3.8)$ & \\
\hline Hyperlipemia & $0(0)$ & $1(3.8)$ & \\
\hline Epidemiological risk history & $7(50)$ & $24(92.3)$ & 0.004 \\
\hline Visit or resident in Wuhan & $5(35.7)$ & $14(53.8)$ & \\
\hline Close contact with COVID-19 & $2(14.3)$ & $10(38.5)$ & \\
\hline \multicolumn{4}{|l|}{ Signs and Symptoms } \\
\hline Fever & $12(85.7)$ & $22(84.6)$ & 0.65 \\
\hline Cough & $5(35.7)$ & $15(57.7)$ & 0.32 \\
\hline Sputum & $2(14.3)$ & $7(26.9)$ & 0.45 \\
\hline Chest tightness & $2(14.3)$ & $3(11.5)$ & 0.58 \\
\hline Fatigue & $2(14.3)$ & $4(15.4)$ & 0.65 \\
\hline Diarrhea & $0(0)$ & $1(3.8)$ & 0.65 \\
\hline Sore throat & $0(0)$ & $2(7.7)$ & 0.53 \\
\hline Incubation period, days & $5(1-13)$ & $8(2-32)$ & 0.12 \\
\hline Viral shedding time, days & $7(3-9)$ & $16(10-36)$ & $\square 0.001$ \\
\hline \multicolumn{4}{|l|}{ Treatment } \\
\hline Antiviral & $14(100 \%)$ & $26(100 \%)$ & NA \\
\hline Antibiotic & $1(7.14 \%)$ & $3(11.54 \%)$ & 1 \\
\hline Corticoid & $1(7.14 \%)$ & $4(15.38 \%)$ & 0.64 \\
\hline
\end{tabular}

Notes: data are mean $\pm \mathrm{SD}$, median (range), number (percentage); P values were analysed with two-tailed t-test and Mann-Whitney test, or chisquare and Fisher's exact test. * one person got both hypertension and diabetes. NA: not available.

Abbreviation: BMI: body mass index; OSAS: obstructive sleep apnea syndrome; CHB: chronic hepatitis B; COVID-19: coronavirus disease 2019; CT: computed tomography.

Table 2. Comparisons of the laboratory measurements and CT features between two groups on admission 


\begin{tabular}{|c|c|c|c|}
\hline Measurements & $\begin{array}{c}\text { Group A } \\
(\mathrm{n}=14)\end{array}$ & $\begin{array}{c}\text { Group B } \\
(n=26)\end{array}$ & $\mathrm{P}$ value \\
\hline White blood cell count, $\times 10^{9} / \mathrm{L}$ & $4.88(2.3-7.45)$ & $4.82(2.78-11.63)$ & 0.75 \\
\hline Neutrophil count, $\times 10^{9} / \mathrm{L}$ & $3.44(1.34-6.27)$ & $3.00(1.24-9.04)$ & 0.93 \\
\hline Lymphocyte count, $\times 10^{9} / \mathrm{L}$ & $0.96(0.63-2.03)$ & $1.28(0.46-2.86)$ & 0.07 \\
\hline Platelet count, $\times 10^{9} / \mathrm{L}$ & $211.5(96-257)$ & $172.5(68-295)$ & 0.045 \\
\hline NLR & $2.9(1.38-6.89)$ & $2.55(0.77-9.17)$ & 0.39 \\
\hline PLR & $195.3(104.5-347.3)$ & 110.21(46.58-323.8) & 0.01 \\
\hline C-reactive protein, $\mathrm{mg} / \mathrm{L}$ & $9.95(0.5-67.83)$ & $1.68(0.49-57.8)$ & 0.027 \\
\hline Hemoglobin, $\mathrm{g} / \mathrm{L}$ & $135.0(110-164)$ & $142.5(73-171)$ & 0.12 \\
\hline Albumin, $\mathrm{g} / \mathrm{L}$ & $39.65 \pm 5.33$ & $41.79 \pm 4.19$ & 0.19 \\
\hline Alanine aminotransferase, U/L & $22.5(9-44)$ & $24.0(12-98)$ & 0.35 \\
\hline Lactic dehydrogenase, U/L & $259.0(168-671)$ & $235.0(127-1081)$ & 0.96 \\
\hline Total bilirubin, $\mu \mathrm{mol} / \mathrm{L}$ & $12.45(5.3-33.4)$ & $13.20(4.4-30.6)$ & 0.44 \\
\hline Serum glucose, $\mathrm{mmol} / \mathrm{L}$ & $5.06(1.08-6.63)$ & $5.58(4.47-10.14)$ & 0.045 \\
\hline Serum urea nitrogen, mmol/L & $4.05 \pm 1.17$ & $4.55 \pm 1.46$ & 0.24 \\
\hline Creatinine, $\mu \mathrm{mol} / \mathrm{L}$ & $70.21 \pm 15.41$ & $69.33 \pm 15.03$ & 0.86 \\
\hline Fibrinogen, $\mathrm{g} / \mathrm{L}$ & $3.99 \pm 1.00$ & $4.68 \pm 1.21$ & 0.08 \\
\hline D-dimer, $\mu \mathrm{g} / \mathrm{ml}$ & $0.36(0.18-1.4)$ & $0.32(0.17-2.91)$ & 0.32 \\
\hline IL-6, pg/ml & $5.38(2.19-20.1)$ & $5.69(2.39-64.6)$ & 0.66 \\
\hline $\mathrm{IL}-2 \mathrm{R}, \mathrm{U} / \mathrm{ml}$ & $435.79 \pm 214.43$ & $512.7 \pm 252.11$ & 0.32 \\
\hline $\mathrm{TNF}-\alpha, \mathrm{pg} / \mathrm{ml}$ & $9.08 \pm 2.78$ & $9.58 \pm 3.36$ & 0.62 \\
\hline $\mathrm{CD} 4, / \mu \mathrm{l}$ & $636.5(220-776)$ & $558.00(225-945)$ & 0.79 \\
\hline $\mathrm{CD} 8, / \mu \mathrm{l}$ & $377.0(155-431)$ & $315.5(129-457)$ & 0.06 \\
\hline $\mathrm{CD} 4 / 8$ & $1.64(0.77-3.09)$ & $1.87(1.1-2.58)$ & 0.019 \\
\hline CT imaging grade & & & 0.45 \\
\hline no lesion & $2(14.3)$ & $3(11.5)$ & \\
\hline unilateral penumonia & $11(78.6)$ & $17(65.4)$ & \\
\hline bilateral pneumonia & $1(7.1)$ & $6(23.1)$ & \\
\hline
\end{tabular}

Notes: data are mean \pm SD, median (range); P values were analysed with two-tailed t-test and Mann-Whitney test, or chi-square and Fisher's exact test.

Abbreviation: NLR: Neutrophil to lymphocyte ratio; PLR: Platelet to lymphocyte ratio; IL-6: interleukin-6; IL-2R: interleukin-2receptor; TNF- $\alpha$ : Tumor Necrosis Factor $\alpha$.

Table 3 Comparisons of the laboratory measurements and CT features between two groups on the $3^{\text {rd }}$ day after treatment 


\begin{tabular}{|c|c|c|c|}
\hline Measurements & $\begin{array}{c}\text { Group A } \\
(\mathrm{n}=14)\end{array}$ & $\begin{array}{c}\text { Group B } \\
(n=26)\end{array}$ & $\mathrm{P}$ value \\
\hline White blood cell count, $\times 10^{9} / \mathrm{L}$ & $5.72 \pm 1.20$ & $5.32 \pm 1.51$ & 0.37 \\
\hline Neutrophil count, $\times 10^{9} / \mathrm{L}$ & $3.87 \pm 1.16$ & $3.38 \pm 1.35$ & 0.24 \\
\hline Lymphocyte count, $\times 10^{9} / \mathrm{L}$ & $1.34 \pm 0.39$ & $1.45 \pm 0.54$ & 0.46 \\
\hline Platelet count, $\times 10^{9} / \mathrm{L}$ & $262.71 \pm 74.10$ & $204.62 \pm 65.53$ & 0.021 \\
\hline NLR & $2.74(1.73-8.44)$ & $2.17(0.87-8.18)$ & 0.29 \\
\hline PLR & 209.03(104.55-325) & $140.44(80-350)$ & 0.018 \\
\hline C-reactive protein, $\mathrm{mg} / \mathrm{L}$ & $10.6(0.3-70.7)$ & $9.51 \square 0.6-77.2 \square$ & 0.88 \\
\hline Hemoglobin, $\mathrm{g} / \mathrm{L}$ & $134.00(113-149)$ & $139.00 \square 83-165 \square$ & 0.20 \\
\hline Albumin, $\mathrm{g} / \mathrm{L}$ & $39.85 \square 28.8-49.5 \square$ & $41.45 \square 34.2-50 \square$ & 0.17 \\
\hline Alanine aminotransferase, U/L & $16.5 \square 9-49 \square$ & $20.0 \square 7-138 \square$ & 0.55 \\
\hline Lactic dehydrogenase, $\mathrm{U} / \mathrm{L}$ & $224.36 \pm 56.47$ & $228.62 \pm 65.39$ & 0.83 \\
\hline Total bilirubin, $\mu \mathrm{mol} / \mathrm{L}$ & $13.1 \square 7.7-29.4 \square$ & $15.6(6.5-44.5)$ & 0.90 \\
\hline Serum glucose,mmol/L & $5.02 \llbracket 3.87-6.58 \square$ & $5.53(3.95-9.77)$ & 0.08 \\
\hline Serum urea nitrogen, $\mathrm{mmol} / \mathrm{L}$ & $4.52 \pm 1.39$ & $4.54 \pm 1.14$ & 0.96 \\
\hline Creatinine, $\mu \mathrm{mol} / \mathrm{L}$ & $76.55 \square 52-92 \square$ & $70.05(48-92)$ & 0.32 \\
\hline Fibrinogen, $\mathrm{g} / \mathrm{L}$ & $4.50 \pm 1.04$ & $4.12 \pm 0.93$ & 0.27 \\
\hline D-dimer, $\mu \mathrm{g} / \mathrm{ml}$ & $0.38 \square 0.18-2.54 \square$ & $0.34 \square 0.16-1.27 \square$ & 0.90 \\
\hline $\mathrm{IL}-6, \mathrm{pg} / \mathrm{ml}$ & $5.01 \square 2.19-16.4 \square$ & $7.76 \square 2.36-64.6 \square$ & 0.015 \\
\hline $\mathrm{IL}-2 \mathrm{R}, \mathrm{U} / \mathrm{ml}$ & $285 \square 220-536 \square$ & $531.5(61.2-2077)$ & 0.039 \\
\hline $\mathrm{TNF}-\alpha, \mathrm{pg} / \mathrm{ml}$ & $6.99 \llbracket 4.34-9.4 \square$ & $10.14(5.26-18.5)$ & 0.001 \\
\hline $\mathrm{CD} 4, / \mu \mathrm{l}$ & $587.93 \pm 157.34$ & $531.15 \pm 175.59$ & 0.31 \\
\hline $\mathrm{CD} 8, / \mu \mathrm{l}$ & $367.07 \pm 66.19$ & $297.38 \pm 107.93$ & 0.016 \\
\hline $\mathrm{CD} 4 / 8$ & $1.60 \pm 0.32$ & $1.89 \pm 0.51$ & 0.035 \\
\hline Changes of CT imaging, degree & & & 0.02 \\
\hline-2 & 0 & 3 & \\
\hline-1 & 3 & 2 & \\
\hline 0 & 3 & 16 & \\
\hline 1 & 6 & 5 & \\
\hline 2 & 2 & 0 & \\
\hline
\end{tabular}

Notes: data are mean \pm SD, median (range); P values were analysed with two-tailed t-test and Mann-Whitney test, or chi-square and Fisher's exact test.

Abbreviation: NLR: Neutrophil to lymphocyte ratio; PLR: Platelet to lymphocyte ratio; IL-6: interleukin-6; IL-2R: interleukin-2receptor; TNF $\alpha$ : Tumor Necrosis Factor $\alpha$.

Table 4. Logistic regression analysis of key factors that may affect the SARS-CoV-2 viral shedding time 


\begin{tabular}{lccc}
\hline Measurments & OR & $95 \%$ CI & P value \\
& & & \\
\hline DemographicMeasurements & & & \\
Comorbidity & $7.54 \mathrm{E} 8$ & $0-\mathrm{NA}$ & 0.99 \\
$\quad$ Epidemiological risk & 7.5 & $1.23-45.81$ & 0.029 \\
Laboratory Parameters & & & \\
$\quad$ On admission & & & \\
$\quad$ Platelet count & 0.99 & $0.98-1.02$ & 0.69 \\
PLR & 0.99 & $0.97-1.00$ & 0.07 \\
CRP & 0.94 & $0.87-1.01$ & 0.81 \\
Serum glucose & 11.41 & $1.14-114.05$ & 0.038 \\
CD4/8 & 9.21 & $1.25-67.86$ & 0.029 \\
$\quad$ 3 day after & & & \\
treatment & & & \\
Platelet count & 1.01 & $0.99-1.02$ & 0.58 \\
PLR & 0.98 & $0.95-1.01$ & 0.13 \\
IL-6 & 1.06 & $0.82-1.36$ & 0.66 \\
IL-2R & 1.00 & $0.99-1.01$ & 0.92 \\
TNF- $\alpha$ & 2.36 & $1.10-5.07$ & 0.027 \\
CD8 & 0.98 & $0.96-1.00$ & 0.025 \\
CD4/8 & 1.12 & $0.045-27.9$ & 0.95
\end{tabular}

Abbreviation: NLR: Neutrophil to lymphocyte ratio; PLR: Platelet to lymphocyte ratio; IL-6: interleukin-6; IL-2R: interleukin-2receptor; TNF $\alpha$ : Tumor Necrosis Factor $\alpha$. NA: Not available.

Figures 


\section{Patient 1}
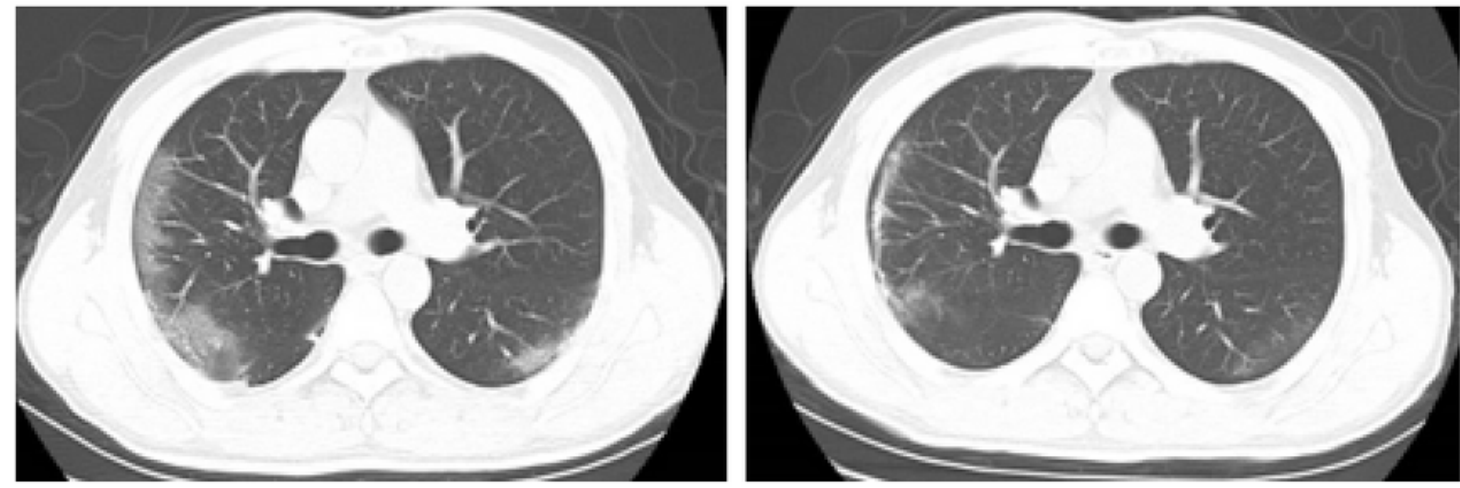

Patient 2
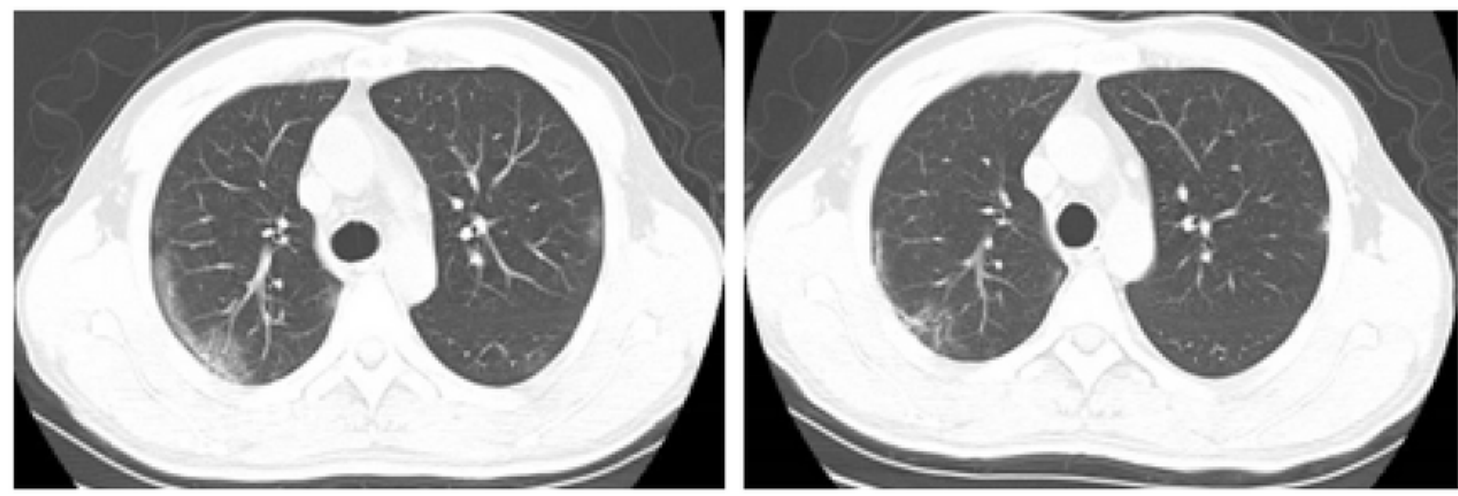

Patient 3
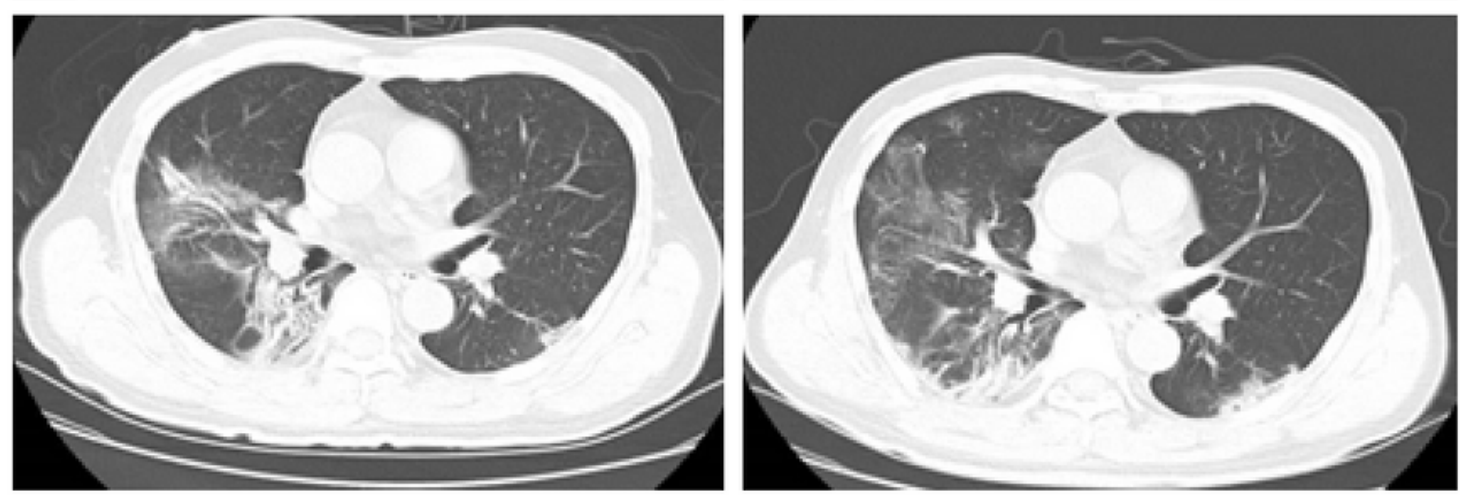

Patient 4
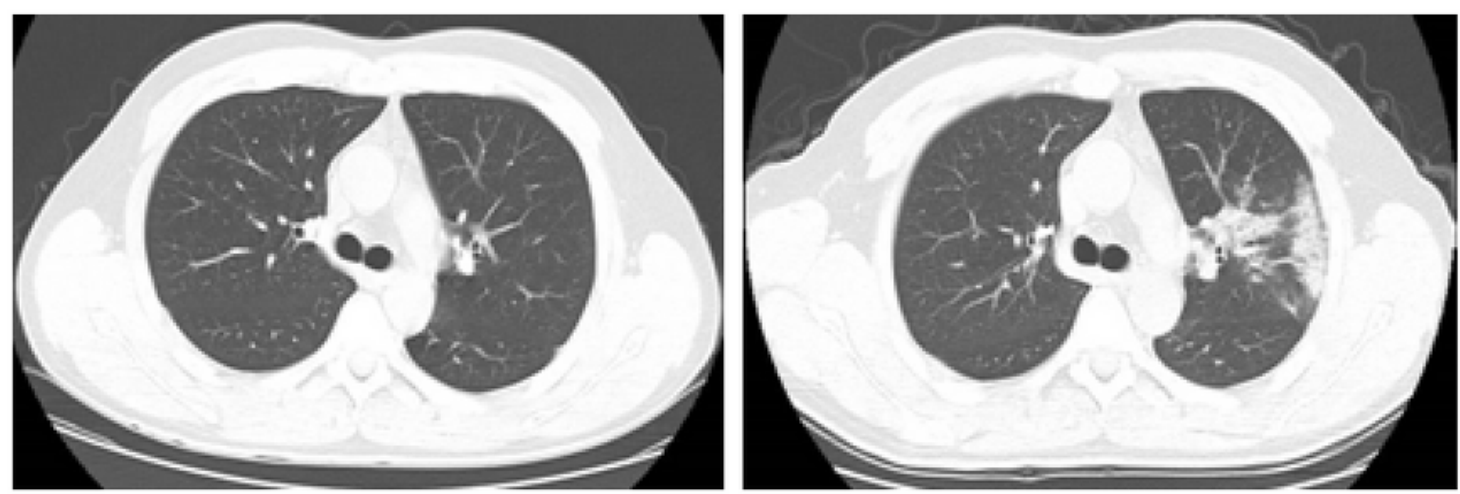

Figure 1

Typical CT imaging of the COVID-19 patients on admission (left) and the 3rd day after treatment (right). The patient 1 displayed bilateral subpleural ground glass opacity on admission and the pulmonary lesion was decreased $60 \%$ on the 3rd after treatment. The patient 2 displayed bilateral subpleural ground glass opacity on admission and the pulmonary lesion was decreased $20-30 \%$ on the 3 rd after treatment. The patient 3 displayed large-scale consolidation with thickened interlobular septa (mainly on the right inferior 
lobe) on admission and the pulmonary lesion was increased $30-50 \%$ on the 3 rd after treatment. The patient 4 displayed single subpleural lesion on admission and the the pulmonary lesion was increased more than $50 \%$ (manifested as large-scale consolidation) on the 3rd after treatment. 